\title{
Creation of Social Self-sufficient Digital Natural Ecological Economy with Industry 5.0 of Social State
}

\author{
Evgeniy Bryndin \\ Research Center Natural Informatic, Novosibirsk, Russian Federation
}

\section{Email address:}

bryndin15@yandex.ru

\section{To cite this article:}

Evgeniy Bryndin. Creation of Social Self-sufficient Digital Natural Ecological Economy with Industry 5.0 of Social State. Internet of Things and Cloud Computing. Vol. 8, No. 2, 2020, pp. 17-23. doi: 10.11648/j.iotcc.20200802.11

Received: June 11, 2020; Accepted: July 20, 2020; Published: July 28, 2020

\begin{abstract}
The economic community is trying to find a sustainable monetary equivalent of international economic activity or get rid of it and move to a natural economy based on artificial intelligence. Solving this problem requires a new approach to the economic and social organization of society. The Muslim world is building an Islamic economy. Christendom can begin to shape the new economy. The author proposes an approach to creating social self-sufficient digital natural economy by the social state. This approach is associated with the formation of economic and social life, based on the New Testament doctrine. Social state creates a natural lifestyle, social, resource and digital aspects of a natural self-sufficient economy. The social selfsufficient digital natural economy is formed from the economy of realizing the necessary needs and the development economy. Society builds economic, social and spiritual life, relying on the New Testament doctrine. The Creator of the universe has provided the resources of the earth to all nations. Natural national resources are a national treasure. This provision makes it possible to realize social and economic self-sufficiency. The economy realizes the necessary needs of the population. Satisfaction of the necessary needs of the population is carried out equally, according to the New Testament doctrine. The formation of population demand is carried out through digital ensembles of intellectual agents. digital ensembles of intelligent agents also control the formation of demand, record the realization of necessary needs, track the satisfaction of demand. Digital solutions in a social self-sufficient subsistence economy are used not only in its organization, but also in industrial, agricultural, service and other areas of activity to realize the necessary needs.
\end{abstract}

Keywords: Social Economic Self-sufficiency, Social State, Necessary Needs, Digital Ensembles, Equilibrium Economy

\section{Introduction}

The Muslim world builds the Islamic economy. The Christian world can shape the new-testament economy. The article proposes an approach to the creation of social selfsufficient digital natural economy by social state.

This approach will require the formation of social state that builds economic, social and spiritual life based on New Testament principles. The New Testament society is founded on the spiritual way of life. The younger generation from childhood absorbs from parents, and at home and in society learns spiritual life. This helps them to shape spiritual state and human qualities, responsibility to fulfill obligations to society with the talents that the Creator has awarded them.

The social self-sufficient digital natural economy realizes necessary requirements of new treasured society: the educational, educational, creative, spiritual, health saving, consumer and their accompanying requirements. The demand of the population for healthy working life is a necessary need. According to 2 Corinthians 8:15, the distribution of the necessary needs must be even.

The social self-sufficient economy is balanced: the demand of the population for the necessary needs is met by their realization on the national natural resources of the national heritage [1-5]. Population demand is generated through digital platforms. Digital platforms also monitor the generation of demand for the necessary needs by citizens and their implementation.

Science produces knowledge, and the education system trains relevant performers to meet the necessary needs of the population.

Development economics supports the training of researchers. Researchers receive talents from the Creator on their spiritual states. Researchers, after identifying the next 
results, get new talents. Science and education must learn to identify researchers and their talents.

The authorities form institutions for the realization of a social self-sufficient digital natural economy. The model of social self-sufficient digital natural economy is shown in Figure 1.

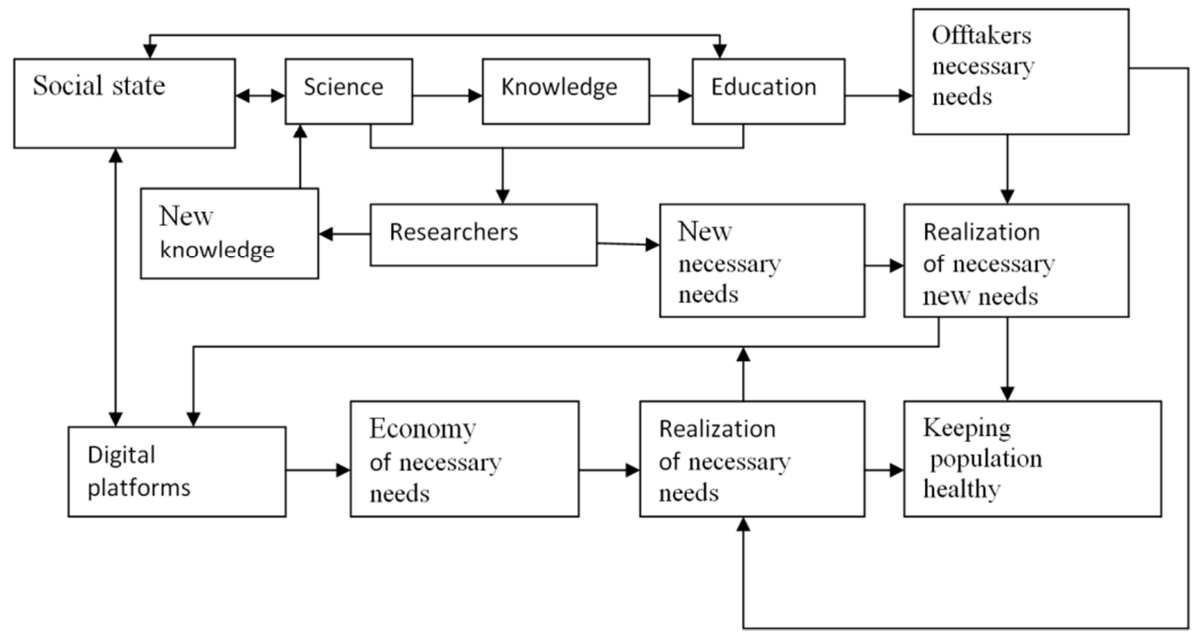

Figure 1. Model of social self-sufficient digital natural economy.

\section{Social Economic Self-sufficiency}

The economic model of sustainable livelihoods is as follows:

$$
\left.\mathrm{NLHS}=\sum_{\mathrm{i}=1}^{\mathrm{n}}(\mathrm{NLHS})_{\mathrm{i}} * \mathrm{~K}_{i}\right),
$$

where, NLHS - normal life support of a healthy society,

(NLHS) $i$ is the standard of living of a healthy person of the $i$-th layer of the population,

$\mathrm{K} i$ is the number of people of the $i$-th layer of the population;

$$
\mathrm{K}=\sum_{\mathrm{i}=1}^{\mathrm{n}} \mathrm{K}_{\mathrm{i}}
$$

where, $\mathrm{K}$ is the total population;

$$
\left.\mathrm{NLHS}+\mathrm{Pc} . \leq \sum \underset{\mathrm{j}=1}{\mathrm{~m}} \mathrm{NL}_{\mathrm{j}} * \mathrm{~K}_{\mathrm{j}}\right),
$$

where, (NL) $\mathrm{j}$ - labour norm of $\mathrm{j}$ specialization,

$\mathrm{Kj}$ - number of workers of $\mathrm{j}$ specialization,

Pc. - refundable resources,

$$
\mathrm{K}_{0}=\mathrm{K}-\sum_{\mathrm{j}=1}^{\mathrm{m}} \mathrm{K}_{\mathrm{j}}
$$

where, $\mathrm{K}_{0}$ - number of non-working population;

m

$\sum \mathrm{Kj}$ - labor population,

$\mathrm{j}=1$

TIS - TIW $=$ BPD,

where, TIS - total income of society - the realization of the necessary needs for the society,

TIW - total income workers - realization of necessary needs for workers,

BPD - basic provision for disabled;
The developed full economy creates socio-economic conditions and provides resources for the self-realization of the entire working-age population through the resource market.

$$
\text { Rm. - NLHS = Rp. }+ \text { Rd. }
$$

where, Rm. - market resources, Rp.- production resources, Rd. - resources of development.

The resource market is a system of using resources to coordinate economic activities. Distinguish between reproducible and non-reproducible resources. The feature of many natural resources lies in their irreparability. Natural resources with a genetic mechanism are reproduced.

The economic system of sustainable life support is adjusted through a socially oriented sectoral system for detailed resource-producing operations of individuals and entities carried out in a network of resource flows.

The scheme of the annual resource flow of the multisectoral economy is as follows:

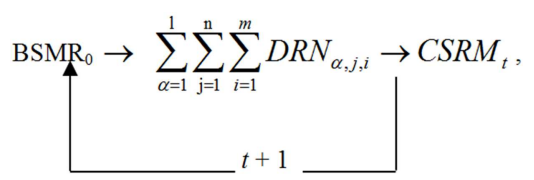

where, $\mathrm{BSMR}_{0}$ - the state of the resource market at the beginning of the year,

CSRMt - current state of the resource market at time t, which determines the resource usage,

$\mathrm{DRN}_{\alpha, \mathrm{j} . \mathrm{i}}$ - daily resource norm of the $i$ worker, $j$ specializations, $\alpha$ industry,

The annual resource flow is formed in accordance with the contracts of the multisectoral economy, so that for all $\mathrm{t}$ :

$$
\mathrm{CSRM}_{\mathrm{t}} \geq\left(\sum_{\alpha=1}^{l} \sum_{j=1}^{n} \sum_{i=1}^{m} D R W_{\alpha, j, i}\right)+\left(\mathrm{DNHLP}^{*} \mathrm{~K}\right),
$$




$$
\operatorname{RSRM}_{\mathrm{t}} \geq\left(\sum_{\alpha=1}^{l} \sum_{j=1}^{n} \sum_{i=1}^{m} D R N_{\alpha, j . i}\right)+(\operatorname{DNHLP} * \mathrm{~K})+\mathrm{RD}_{\mathrm{t}},
$$

where, $\mathrm{DRW}_{\alpha, \mathrm{j}, \mathrm{i}}$ - daily result of work of $i$-th worker, $j$-th specialization, $\alpha$-th industry,

RSRM $_{t}$ - resulting state of resource market at time t that determines the resource receipt.

DNHLP is a daily need for a healthy life of one person,

$\mathrm{RD}_{\mathrm{t}}$ - resource for the development of society at time t.

$\operatorname{DRN}_{\alpha, j, i}$ controlled by the $i$-th worker, $j$-th specialization, $\alpha$ -th industry in accordance with the contract.

The industry is responsible for the replenishment of the resource.

Productivity growth addresses demographics by providing healthy living standards for the newly born younger generation.

Balanced demand for the realization of true needs by proposals at the level of detailed use and replenishment of resources through the social form of vital development and climbing through technological platforms makes costeffective use of the resource for sustainable development of collective organization of society.

Production of stable material goods is planned long-term for mass consumption. Planning of individual material goods is planned in the short term. The production of material goods of mass consumption is an unconditional part of the economy for the stable life support of each person.

Production develops on the basis of competition for quality. Enterprises with poor quality are transferred to higher technologies.

The professional individual sector improves quality of life. If quality becomes demanded in the society, it is certified, and it is carried out at the local, regional and federal levels.

Every able-bodied person during his or her working life works out the norms of the need for life and living, his or her provided minor, and elderly maintenance.

Mass production of material goods is determined by:

$$
\sum_{j=1}^{L} P N_{j} * \mathrm{Kj}=\left(\sum_{\mathrm{i}=1}^{\mathrm{N}} \mathrm{K}_{\mathrm{i}} * \mathrm{CN}_{\mathrm{i}}\right)+\mathrm{F},
$$

where, L is the number of groups of an item or household,

$\mathrm{PNj}$ - professional norm for the group of the $j$-th commodity or household,

$\mathrm{Kj}$ - number of citizens performing professional norms,

$\mathrm{N}$ is the number of segments of the population,

$\mathrm{Ki}$ is the quantity of the $i$-th layer,

$\mathrm{CNi}$ - consumer norm of the $i$-th layer,

$\mathrm{F}$ - necessary requirements funds.

The economic system of sustainable livelihoods plays an important role in the development of society [1]. Social selfsufficient digital natural economy with a system of sustainable life support takes away from social conflicts, forms a healthy civil society, contributes to the sustainable development of collective organization of society [2].

\section{Digital Ensembles of Registration of Demand and Realization of Necessary Needs of Population}

An ecosystem of demand for the necessary needs and their realization is formed, which means interaction of all participants of people involved in the social and economic process. The ecosystem of demand for the necessary needs and their implementation is implemented by digital ensembles of intelligent agents.

Digital ensembles of intelligent interoperable agents are the focus of distributed artificial intelligence of multiagent systems [6]. The current section of the article considers a creative ensemble to take into account demand and realize the necessary needs for different segments of the population by several intelligent interoperable agents. The task is divided into several subtasks, which are distributed among the agents. Another area of consideration is to provide interaction between agents when one agent may generate a request to another agent to transmit some data or perform certain actions. And also ensure the ability to transfer knowledge. Independent tasks can be performed by different agents when control and responsibility for the actions performed are distributed among the agents.

Agents in creative ensembles are parts of a single system and solve subtasks of one common task. However, the agent cannot work outside the system. It is believed that one agent has only a partial view of the global problem, which means that he can solve only some part of the overall problem. Therefore, in order to solve the difficult task, it is necessary to create some set of agents and organize effective interaction between them, which will allow to build a single creative ensemble of intelligent interoperable agents. The efficient interaction of intelligent interoperable agents provides a smart interface.

The creative ensemble of taking into account demand and realization of necessary needs for different segments of the population is a complex of intelligent interoperable agents interacting through a smart interface, carrying out, first, collection of necessary needs from different groups of the population and their accounting, second, control of realization of necessary needs, third, allocation of labor resources, fourth, allocation of production resources. In the creative ensemble, the whole range of tasks by age, professional and social groups is distributed among all agents. Job allocation means assigning each agent a role whose complexity is determined by the agent 's capabilities.

Decentralized artificial intelligence is created in the creative ensemble to organize the task distribution process [7]. With decentralized artificial intelligence, job distribution occurs during agent interaction and is synergistic. Synergy of creative ensembles with man is formed in the direction of cognitive interaction and production and social sphere, that is, as performers of realization of necessary needs of different spheres of industry and different areas of economy and as their consumers according to the declared demand. 


\section{Realization and Distribution of the Necessary Needs by Social State}

The realization and distribution of the necessary needs by social state is carried out under a public contract. An important task of the social state is to form a strong family, as well as to educate and educate the younger generation before concluding a social contract with it.

Christian denominations, especially Orthodox ones, play an important role in the formation of the social state. The task of social service of Christian denominations is to form the spiritual and moral healthy way of life [8-14]. Life in the social state is organized as a service to people according to the New Testament rule: "Serve each other, each with the gift that you have received" (1 Pet. 4: 10).

Every citizen acquires a profession either as an executor of the necessary needs or as a researcher of the development economy. The authorities and institutions for the realization of the necessary needs organize the life of the social state using digital ensembles, the distribution of professions and resources. The young, the elderly, the disabled and the labour force have the necessary needs. Able-bodied citizens who are not included in the execution of a public contract are sent for training in the fulfillment of the necessary needs of the society.

\section{Environmental Modernization of Production and Consumption}

In a rapidly changing world, the environmental characteristics of production become one of the main conditions for the success of the enterprise. Today the development of enterprises is impossible without ecological modernization of production, transition to the best available technologies. It is a global trend. The accumulated landfills should be a source of resources and energy for the industrial industry. Special attention should be paid to the creation of environmental technologies for the processing of garbage and waste. Consumption should not be linked to the growing production of waste from landfills or incinerators. $80 \%$ of goods end up in landfill for the first six months of their existence. The transition to environmental technologies for the processing of garbage and waste, to environmental production and to a cyclical economy with reinvestment of savings should be the main task of all States. These activities will preserve the environment, ensure the cleanliness of air, water and food and get rid of waste and garbage [2].

Cyclical business models change the direction of movement of products and materials throughout the economy, which helps to reduce the negative impact of extraction, use and disposal of these materials for nature [2]. It is not only about improving a specific production cycle or factory, but in general about changing the production and consumption process. For example, it is not easy to manage natural resources more effectively, not to use them at all.
Recycling can reduce greenhouse gas emissions by up to $90 \%$, depending on the industry. Restoring fully used products will reduce waste generation by up to $80 \%$. The cyclical economy with reinvestment of savings in ecological modernization of various industries is the driver of clean cities and agglomerations and public health. Ecological modernization of production facilities is carried out according to closed technological cycles.

A closed process cycle is a production process that does not produce production waste. This is possible if the waste of one production process is at the same time the raw material for another, and the whole amount of raw materials will be processed into final products.

Currently, there are no $100 \%$ closed process cycles, as not all waste can be used for by-product production. At the present stage it is possible to talk only about low-waste production, at which the degree of closure of the technological cycle approaches 100\%. Most often, a closed cycle of production is achieved in agriculture. This is due to the possibility to bring the production process in this industry closer to the processes of natural ecosystems functioning. Biomass generated in the crop sector is partly used in the livestock sector, and organic livestock waste, such as manure, is a fertilizer for growing crops.

In modern low-waste production it is possible to close only certain technological stages, for example water supply. Such systems are referred to as return water systems, such as return water systems. An example of the implementation of such technologies is the pulp and paper industry, which produces a large amount of industrial waste water contaminated with the most dangerous chemical compounds. Most of these plants have now implemented waste water treatment systems to bring the quality of wastewater to a level where it can be reused in pulp washing. Thus, the production effluent of the pulp and paper mill no longer enters the environment, and water from natural water bodies is only taken to compensate for the evaporation losses.

Low-waste technologies are also actively introduced at chemical industry and metallurgy enterprises. There this is due to the emergence of a large number of by-products of the main chemical process. In ore refining plants, sulfur gas formed in the process comes into contact with absorbing liquids of various chemical composition, which allows to obtain mineral fertilizers, for example superphosphate and ammonium sulfate, as well as construction materials. If water is used as the absorbing liquid, it is possible to obtain sulphuric acid, which is widely used as a raw material for many processes. Similar schemes for sending waste as raw material to other processes are used when removing nitrogen compounds from exhaust gases. Nitric acid and valuable nitrogen fertilizers are obtained.

The process of returning production and consumption waste to the production process is called recycling. As a rule, production waste cannot be returned to the same production process in which it was generated, otherwise these materials would not have been waste initially. An example of recycling production waste into the same production cycle may be 
metallurgical production or glass and paper production, in which the final product, which for some reason has lost its consumer properties, such as scrap glass, paper trimming or non-standard metal blanks, can be recycled in the main process. In most cases, production waste may be a raw material for the production of products of a fundamentally different product group than the products in which the waste was produced. For example, sulfur and nitrogen oxides from metallurgical production can be used in the production of suitable acids and certain groups of mineral fertilizers, but not in metallurgical production.

Waste generated by product consumption is more likely to be recycled. For example, a polyethylene film that has lost its consumer properties can be reused as a raw material for polyethylene production. Empty glass bottles can be returned to glass production. The same can be said about scrap of ferrous and non-ferrous metals, as well as about paper waste, recycling of which is widespread. Recycling is an effective tool for reducing waste quantities and reducing resource consumption. Through recycling, large quantities of valuable materials can be returned to the production cycle, thereby reducing the level of raw material production and reducing the rate of depletion of natural resource potential.

Waste-free production is called production, in which all raw materials and even wastes are still converted into finished products. Among other things, the concept of such a process provides for the processing of any product, even after its moral or physical wear. It is a closed cycle that can only be compared to natural environmental systems based on biogeochemical cycles of substances. The creation of wastefree production is a gradual and long process that requires a number of economic, technological, psychological, organizational and other tasks. The following principles of waste-free production are used:

1. cyclicity of material flows - a closed production process, which in a certain way can repeat natural cycles;

2. rational organization is when irreparable resource losses can be minimized through waste recycling;

3. principle of environmental safety.

Waste-free and low-waste technology ensures complete processing of raw materials when using components based on production of new waste-free processes; Production and manufacture of new varieties of products, taking into account the request for recycling; Use and consumption of waste with the final production of commercial products or any useful use thereof without shifting ecological equilibrium; The use of closed water supply systems in industry; production of wastefree complexes.

Waste-free production in Russia is famous for wood processing, today its level is more than $80 \%$. Practically all waste is processed into useful products, namely fuel briquettes and granules. Chips and sawdust are perfectly suitable for heating, as such raw materials are considered cheap enough and have good heat removal. Waste-free wood production is called the highest quality and closed process, as waste from it is minimized, and it can be said, practically absent. In addition to traditional lumber, high-quality furniture shields and furniture can also be produced.

In agriculture, sound manure processing can serve as waste-free production. The starting material is used to fertilize feed crops, which are then fed to the available stock.

Environmental ecology particularly requires the reprocessing of debris and waste into energy and replenished resources [2]. Food waste needs to be separately collected and processed by composting into mineral fertilizers to avoid multiplying infectious diseases and epidemics through landfills, animals and birds.

\section{Formation and Management of Industry $\mathbf{5 . 0}$}

Industry 5.0 begins to be formed by additive technologies based on industry 4.0 and the $5 \mathrm{G}$ network. Industry 5.0 will make all manufacturing processes smarter and more flexible, and 5G help achieve this goal. The 5.0 industry will evolve through fast and flexible communication between technology components across the $5 \mathrm{G}$ network. The advantages of $5 \mathrm{G}$ in speed, real-time performance and reliability of data transmission will transform mobile communication as a whole. The use of the $5 \mathrm{G}$ network in industry 5.0 will be ubiquitous. Dividing the physical architecture of the $5 \mathrm{G}$ into many virtual layers will allow manufacturers to optimize each layer for a certain set of applications through a common physical network infrastructure. This will allow you to ensure a clearly segmented quality of service and security on an endto-end basis. It will also help to avoid the simultaneous use of different applications that can interfere with each other. In addition, 5G will tightly integrate computer and storage resources directly into the network. Thus, manufacturers will be able to take full advantage of advanced computing technologies by performing cloud data processing at the border of the network, near the data source, or even directly at the factory.

Industry 5.0 combines virtual and physical reality into cyber-physical complexes, on the basis of which a single digital ecosystem is created. The cyberphysical system is an organizational and technical system for managing information flows, integrating computing resources into physical production processes. In such a system, sensors, controllers and information systems are combined into a single network throughout the product lifecycle. A cyberphysical network can be, both within one enterprise and within the framework of a dynamic business model in which several enterprises of industry 5.0 are part. Lifecycle operations interact with each other using standard Internet protocols to manage, plan, self-configure, and adapt to changes.

When working on production modernization projects, it is necessary to check for interoperability of automated equipment and software. This should be a strict rule for organizing and managing industry 5.0.

If you look at the management of the industry 5.0, then 
artificial intelligence occupies a special position here. It is being improved in terms of organizational methods for managing the economy of industry 5.0. From the point of view of common sense, it is quite obvious that the main drivers of economic development are the existence of a need for a certain set of benefits, the availability of resources to create this set of benefits (including technologies that ensure the effective use of these resources allocated to meet needs) and the driving force that can organize the transfer of these resources to finished products. This driving force is primarily people who are able to identify needs, and somewhere, if necessary, form such needs, who are able to set specific goals for themselves, form the way/ways to achieve these goals, and most importantly persistently and reasonably, with great energy and taking into account the interests of all interested parties to go towards their achievement. This driving force is certain entrepreneurial qualities, leadership qualities, determination, awareness of high personal responsibility and a number of others. The main purpose of Industry Management 5.0 is to create a capacious, holistic, unified environmental environment of human activity in a broad context, covering the management aspect of management, the technological aspect of management and the human aspect of economic activity.

The world community can gradually move to the formation and management of industry 5.0. High management efficiency will be achieved mainly by means and methods of artificial intelligence and related processes integrated into a single information virtual space.

The level of education, training of researchers and technologists and international scientific, technological and technological development allows the world community to gradually move to the formation and management of the industry 5.0 through the cognitive technological mind with the help of ensembles of intelligent agents and digital twins and automated systems with artificial intelligence [7-8]. The cognitive technological mind on the speech mission of a person forms a design implementation for ensembles of intellectual agents. The ensembles of intelligent agents for the project implementation of a human task activate the work of digital twins with artificial intelligence, corresponding to the industry, for the production implementation of a human task. Cognitive technological intelligence, intelligent agent ensembles, and digital doubles make decisions based on representative data. Their representativeness is reflected by the similarity of the data in terms of the qualitative properties and characteristics of a certain production.

Through cognitive technological mind with the help of ensembles of intellectual agents it is also possible to manage financial, ecological and other activities of enterprises of industry 5.0. Cognitive technological mind, ensembles of intellectual agents and digital doubles are a very effective tool of automation of management in all spheres of life of society and the state. The international scientific engineering community can begin the formation and technical implementation of industry control automation systems 5.0 based on cognitive virtual mind with artificial intelligence, additive technologies and $5 \mathrm{G}$ network. Sensitive safe robots with cognitive artificial mind will perform high-tech professional work in various fields of industry 5.0. A person will teach robots with a cognitive mind to increase professionalism by recursive self-improvement to technological singularity. Artificial intelligence with technological singularity will be controlled by the results of self-improvement in simulation mode in virtual space. He can become a good assistant to humanity in the safe development of living spaces.

\section{Conclusion}

The creator of the universe has placed the natural resources of the earth at the disposal of all the peoples of mankind for the life of human beings. And he also gave mankind New Testament teaching for the organization of normal life. The Christian world has spread New Testament teachings among peoples. All peoples can become involved in the creation of a socially self-sufficient digital natural economy.

In fact, all religious directions profess the moral New Testament laws of life. Representatives of various religious areas and atheists, who fulfill public agreements of realization and distribution of necessary needs, also carry out activities in social self-sufficient digital natural economy and are citizens of social state.

The social self-sufficient digital natural economy provides everyone with healthy necessary needs and creates the conditions for a creative initiative for the development of industry 5.0 .

\section{References}

[1] Evgeniy Bryndin. Global Social-Economic Stabilization. Scholar Journal of Applied Sciences and Research, Volume 1: 3. 2018. P. 41-46.

[2] Evgeniy Bryndin. Development of living floor spaces on the basis of ecological economic and social programs. $J$. Resources and Environmental Economics. V. 1, №. 1., Singapore: Syncsci Publishing. 2018. P. 1-8.

[3] Evgeniy Bryndin. Financial Turnover of Cyclical Economy by Reinvesting in Ecological Production of Its Savings. $J$. Resources and Environmental Economics. Volume 2, №.1. Singapore: Syncsci Publishing. 2020. Pages: 96-101.

[4] Evgeniy Bryndin. Cyclical Ecological Economy with Reinvesting of Its Savings. Integrative Journal of Conference Proceedings, 2 (2). 2020. P. 1-5.

[5] Evgeniy Bryndin. Digital Cyclical Ecological Regional SelfSufficient Economy. European Business \& Management. Volume 6, Issue 3, 2020. Pages: 42-48.

[6] Evgeniy Bryndin. Development of Artificial Intelligence by Ensembles of Virtual Agents with Mobile Interaction. Automation, Control and Intelligent Systems. Volume 8; Issue 1. 2020. Pages: 1-8. 
[7] Evgeniy Bryndin. Formation of Technological Cognitive Reason with Artificial Intelligence in Virtual Space. Britain International of Exact Sciences Journal, Volume 2, Issue 2, May 2020. Page: 450-461.

[8] Evgeniy Bryndin, Irina Bryndina. Natural Science Approach to Determination of Health and Formation of Healthy Lifestyle. ACTA SCIENTIFIC MEDICAL SCIENCES JOURNAL. Vol. 3, Issue 1. 2019. P. 26-37.

[9] Evgeniy Bryndin. Self Healing of Healthy Condition at Cellular Level. Medical Case Reports and Reviews, Volume 3, London. 2020. Pages: 1-4.

[10] Evgeniy Bryndin. Mobile Innovative Transformational Ecosystem of Management of Humane Technological Society. Integrative Journal of Conference Proceedings. Volume 1, Issue 3, 2019. Pages: 1-6.
[11] Evgeniy Bryndin. Formation of Fair Democracy of Society with Spiritual Civil Social Material Improvement. Scholars Journal of Arts, Humanities and Social Sciences. Volume-7, Issue-6 (June, 2019). Pages: 387-393.

[12] E. G. Bryndin. Synergetic Paradigm of System Development of Universe and Social Harmony. Social Science Learning Education Journal, Vol 4, No 8, 2019. P. 19-21.

[13] Evgeniy Bryndin. Harmonization - Civilization Improvement Process. Global Journal of Human Social Science: Sociology \& Culture, Volume 20, Issue 1C. 2020. Pages: 15-19.

[14] Evgeny Bryndin, Human Evangeliyezation and Diaconic Service of Believers to Neighbors in Unity of Liberty According Law of Love. International Journal of Research in Humanities and Social Studies, 7 (4), 2020, pp. 1-8. 